\title{
Typical artificial Hippophae rhamnoides forest soil microbial response to the soil environment of abandoned cropland in the Loess Plateau
}

\author{
Xiaohua Liu ${ }^{1}$ and Tianxing $\mathrm{Wei}^{1}$ \\ ${ }^{1}$ Beijing Forestry University
}

June 4, 2020

\begin{abstract}
This study aimed to analyze the characteristics of soil microbial communities of Hippophae rhamnoides forest during the revegetation of abandoned cropland in the Loess Plateau in China. We used high-throughput sequencing technology to analyze the carbon $(\mathrm{C})$ and nitrogen $(\mathrm{N})$ characteristics of soil microorganisms and the relationship between the soil environment and the soil microbial community structure in pure and mixed Hippophae rhamnoides forests in Wuqi County, Shaanxi province. The findings revealed that soil microbial $\mathrm{C}$ and $\mathrm{N}$ in different soil layers showed a decreasing trend with an increase in soil layers and the structural difference of the soil microbial community among different forest stands in the study area was smaller than that among different soil layers. Gracilibacteria, Gemmatimonadetes, Nitrospirae, Parcubacteria, and Actinonobacteria in bacteria were significantly correlated with soil environmental factors. Ichthyosporea and Ciliophora in fungi were strongly affected by environmental factors. The effect of environmental factors on bacteria is greater than that on fungi. Our findings can provide some data to support and feasible suggestions for studies on revegetation in the Loess Plateau.
\end{abstract}

Typical artificial Hippophae rhamnoides forest soil microbial response to the soil environment of abandoned cropland in the Loess Plateau

Xiaohua Liu, Tianxing Wei11Corresponding author. E-mail address:weitx@bjfu.edu.cn(Tianxing Wei)

School of Soil and Water Conservation,Beijing Forestry University, Beijing, 100083, PR China

Abstract :This study aimed to analyze the characteristics of soil microbial communities of Hippophae rhamnoides forest during the revegetation of abandoned cropland in the Loess Plateau in China. We used high-throughput sequencing technology to analyze the carbon (C) and nitrogen (N) characteristics of soil microorganisms and the relationship between the soil environment and the soil microbial community structure in pure and mixed Hippophae rhamnoides forests in Wuqi County, Shaanxi province. The findings revealed that soil microbial $\mathrm{C}$ and $\mathrm{N}$ in different soil layers showed a decreasing trend with an increase in soil layers and the structural difference of the soil microbial community among different forest stands in the study area was smaller than that among different soil layers. Gracilibacteria, Gemmatimonadetes, Nitrospirae, Parcubacteria, and Actinonobacteria in bacteria were significantly correlated with soil environmental factors. Ichthyosporea and Ciliophora in fungi were strongly affected by environmental factors. The effect of environmental factors on bacteria is greater than that on fungi. Our findings can provide some data to support and feasible suggestions for studies on revegetation in the Loess Plateau.

Keywords:Revegetation; High-throughput sequencing; Soil microbial community; Soil environment; The Loess Plateau

\section{Introduction}


Ecological restoration is a complex process that involves improvement of green vegetation coverage, prevention of soil erosion, and reduction of natural disasters. Currently, revegetation is a hot topic of research in ecology, encompassing soil physical and chemical properties and soil and water conservation (Zeng et al., 2014), ecological stoichiometric characteristics of vegetation and soil (Jiao et al., 2013), soil nutrient element preservation (Ma et al., 2014), biodiversity of undergrowth vegetation (Chen and Cao, 2014), and soil microbial communities (Zhang et al., 2010). As the agents of decomposition in the ecosystem, soil microorganisms play a key role in forest succession and nutrient cycling. They are the link between the aboveground and underground components of the ecosystem and represent an important index for evaluation of ecosystem restoration (Wardle, 2004; Lewis et al., 2010; Van der Heijden et al., 2008). Plant community in forest ecosystems by changing the species composition, biomass, litter-earth system components, forest and soil environment factors, such as soil microbial community structure and composition (Okubo et al., 2016; Prescott and Grayston, 2013; Spohn and Widdig, 2017; Ushio et al., 2013), and many relevant studies have reported the species and soil physical and chemical properties of soil microbial community composition and diversity (Ding et al., 2017; Nacke et al., 2016; Pei et al., 2016; Zhalnina et al., 2015).

With the development of soil microbial research methods, high-throughput sequencing technology, also known as either "next-generation sequencing technology" or deep sequencing, has gradually become a conventional method for analyzing the diversity of soil microorganisms. Currently, this method is used widely to determine the effects of vegetation, crop cultivation and land management, organic pollutants, heavy metals, seasonal changes, climatic conditions, and other factors on soil microbial community structure and biomass (Ren et al., 2018; Zeng et al., 2016; Zhang et al., 2016, 2018).

It is a long-term and arduous task to harness the ecological environment and restore the vegetation in the Loess Plateau. Revegetation is not only the first step in ecosystem reconstruction but also an important measure of ecological environment management and soil and water conservation on the Loess Plateau, and it can effectively reduce soil erosion and improve soil quality (Fierer and Jackson, 2006; Xing et al., 2013). Wuqi County in Shaanxi Province is located in an interlaced area of wind erosion and water erosion on the Loess Plateau. In that area, the soil erosion is serious and the ecological environment is fragile. Since 1998, the government has adopted a development strategy based on "closing hills and returning farmland, afforestation to grass, indoor sheep production, and by planting trees to move out of poverty." The change in vegetation development and species composition in Wuqi County following the closure reflects the trend of increasing stability of the degraded matrix and enhancement of the community environment (Luo, et al., 2006).

In recent years, the revegetation project on the Loess Plateau has increased the area of vegetation considerably, and an increasing number of studies have examined the revegetation of the returned farmland in this area (Chen et al., 2015; Deng et al., 2015; Feng et al., 2013; Feng et al., 2016; Kou et al., 2016; Nie et al., 2015; Song et al., 2015). In general, these studies have focused on the impacts of revegetation on soil properties, changes of species diversity, the benefits of soil and water conservation, and the allocation mode of revegetation in the process of land restoration. However, there has been no systematic analysis of the interaction between revegetation, soils, and microorganisms in the process of land restoration.

Hippophae rhamnoides, which is a pioneer and associated species of vegetation structure in the Loess Plateau, has clear ecological and economic benefits. Its root system can co-exist with nitrogen (N)-fixing actinomycetes to form N-fixing nodules and fix free N. Furthermore, this root system can decompose insoluble organic matter and minerals, thereby helping to improve the soil (Hu et al., 2014; Hu, 2012; Li et al., 2003).

Therefore, to determine feasible strategies for revegetation in Wuqi County, we used high-throughput sequencing technology to analyze the characteristics of soil microbial carbon (C)and $\mathrm{N}$ elements and the relationship between soil microorganisms and the soil environment in the area, taking the pure and mixed H. rhamnoides forests as the research object and bare grassland as a control.

\section{Materials and methods}

\subsection{Study site and sampling}


The study site is located in Dajigou Forest Park of Wuqi County (107'38'57" "108deg32'49"E, 36deg33'33" $37 \mathrm{deg} 24 ' 27$ 'N), Yan'an City, Shaanxi Province, China, and at the southern margin of Maowusu Desert, with little vegetation cover and few people. The elevation of Wuqi County ranges from $1350 \mathrm{~m}$ to $1525 \mathrm{~m}$. From 1957 to 2014, the average precipitation was $469.68 \mathrm{~mm}$, and $87 \%$ of this rainfall fell during 5-10 months of the year. The average annual temperature is $8.04 \mathrm{degC}$ (Zhao et al., 2018). The vegetation types in the area are characterized by the transition from forest shrub steppe vegetation to steppe forest shrub steppe vegetation. The vegetation composition is dominated by the flora of North China. Since the project of returning farmland to forestry was implemented, there vegetation coverage has increased significantly. We selected different $H$. rhamnoides forests as the research objects. We selected typical sample plots were in stands and set up $20 \mathrm{~m} \mathrm{x} 20 \mathrm{~m}$ arbor sample plots to observe and record the position (coordinate information, altitude) and site condition (such as slope and canopy closure) of the sample site in August 2017. Table 1 shows the specific situation. At each sampling site, we collected soil from three locations ca. $20 \mathrm{~m}$ apart from one another by pooling five soil cores from $1 \mathrm{mx} 1 \mathrm{~m}$ area at each location. The surface soil samples were collected from each quadrat at random and mixed immediately to form a single soil sample. Visible matter, such as loose gravel and plant debris, was removed and divided into two parts. One part was passed through a $2 \mathrm{~mm}$ sieve into a $15 \mathrm{~mL}$ centrifuge tube, placed into a liquid $\mathrm{N}$ canister, transferred to the laboratory, and stored in a freezer at $-80 \mathrm{deg} C$ for microbial analyses. The other part was subjected to air-drying treatment and used to determine soil nutrients.

\subsection{Soil sample determination}

\subsubsection{Sequencing of soil microbial genes}

Extraction of DNA: Genomic DNA was isolated from $0.5 \mathrm{~g}$ of each soil sample from each sample site using the FastDNA SPIN Kit for Soil (MP Biomedicals, CA, USA) and following the manufacturer's instructions. Extracts of three technical repeats were mixed into a single DNA sample. Extracted genomic DNA was detected by $1 \%$ agarose gel electrophoresis. DNA concentration and purity were measured using an ultramicro spectrophotometer (Nano Drop2000, US).

PCR amplification:Based on previous reports, we used the primers 338F-806R for the $16 \mathrm{~S}$ rRNA of bacteria and the primers SSU0817F-1196R for the $18 \mathrm{~S}$ gene of fungi. Amplified products were detected by $2 \%$ agarose gel electrophoresis, recovered from the gel using the AxyPrep DNA gel extraction kit (Axygen Biosciences, Union City, CA, USA), washed with Tris- $\mathrm{HCl}$, and verified by $2 \%$ agarose gel electrophoresis.

We quantified PCR products using the QuantiFluorTM-ST Fluorometer (Promega Biotech, Beijing, China) and adjusted the samples as required for sequencing. We performed high-throughput sequencing using Illumina Miseq PE300 platform (Shanghai Majorbio Bio-Pharm Technology Co., Ltd, China).

\subsubsection{Soil microbial carbon and nitrogen determination}

Soil microbial biomass $\mathrm{C}$ and $\mathrm{N}$ were determined via fumigation extraction (Vance et al., 1987). Equivalent amounts of soil were weighed and used for either fumigation or non-fumigation, and the fumigation was conducted for $24 \mathrm{~h}$ under vacuum at 25 . After $0.5 \mathrm{~mol} / \mathrm{L} \mathrm{K2SO} 4$ extraction, TOC analysis was performed. Soil microbial $\mathrm{C}$ and $\mathrm{N}$ contents were calculated based on the difference between fumigation and nonfumigation. The calculation formula is as follows.

$\mathrm{BC}=\frac{(\text { TOCfumigation }- \text { TOCnonfumigation })}{0.45}$

\subsubsection{Determination of soil physical and chemical properties}

We determined soil organic matter content using the potassium dichromate volumetric method, soil total $\mathrm{N}$ using the semi-micro Kjeldahl method, soil total phosphorus (P) using the sulfuric acid perchloric acid digestion molybdenum-antimony anti-colorimetric method, soil available $\mathrm{P}$ using the molybdenum-antimony anti-colorimetric method extracted by sodium bicarbonate, soil available potassium (K) using ammonium acetate flame spectrophotometry, and soil alkali-hydrolyzed $\mathrm{N}$ using the alkali-hydrolyzed diffusion method (Wei et al., 2014). 


\section{Results and analysis}

\subsection{Analysis of soil microbial carbon and nitrogen in different $H$. rhamnoides forests}

\subsubsection{Characteristics of soil microbial carbon and nitrogen in different $H$. rhamnoides forests}

As shown in Table 2, our analysis revealed that soil microbial $\mathrm{C}$ and $\mathrm{N}$ content in different soil layers showed a trend of small change with increasing soil layers. That is, soil microbial activities weakened gradually as the soil depth increased. There was a slight increase in soil microbial C content in the $60-80 \mathrm{~cm}$ soil layer of $H$. rhamnoides pure forest (shady slope), the $80-100 \mathrm{~cm}$ soil layer of $H$. rhamnoides pure forest (sunny slope), the 80-100 cm soil layer of $H$. rhamnoides and Chinese arborvitae mixed forest and the $60-80 \mathrm{~cm}$ soil layer of $H$. rhamnoides and Pinus tabulaeformis mixed forest. There was no clear vertical variation of soil microbial $\mathrm{N}$ content, and there was no significant difference between different soil layers. Over the four plots, the soil microbial C content was highest in H. rhamnoides pure forest (sunny slope), whereas there was little difference in the soil microbial $\mathrm{C}$ contents of the other three plots. Soil microbial $\mathrm{N}$ content was highest in H. rhamnoides pure forest (sunny slope), and the lowest value was in H. rhamnoides and P. tabulaeformis mixed forest.

3.1.2 Regression analysis of soil microbial carbon and nitrogen contents and soil carbon and nitrogen contents in different $H$. rhamnoides forests

Regression analysis, as a method for statistical analysis of the inter-dependent quantitative relationship between two or more variables, can be used to analyze the relationship between one variable and the change of another variable. We analyzed the soil microbial $\mathrm{C}$ and $\mathrm{N}$ content and the soil $\mathrm{C}$ and $\mathrm{N}$ content in different $H$. rhamnoidesforests via exponential and linear regression analysis and established a regression model. Table 3 shows the results. Apart from the H. rhamnoides and P. tabulaeformis mixed forest, the regression equations of the other three samples were well fitted. Of the three well-fitting plots, the $\mathrm{R}^{2}$ of the index model of soil microbial biomass $\mathrm{N}$ and alkali-hydrolysable $\mathrm{N}$ of $H$. rhamnoidespure forest (sunny slope) was 0.73 , whereas the remainder were all above 0.8 , with some even exceeding 0.9 . Therefore, the model can well explain the relationship between soil microbial $\mathrm{C}$ content and soil organic $\mathrm{C}$ content, soil microbial $\mathrm{N}$ content and soil total $\mathrm{N}$ content, and soil microbial $\mathrm{N}$ content and alkali-hydrolyzed $\mathrm{N}$ content. Only the soil microbial $\mathrm{N}$ content and soil alkali-hydrolyzed $\mathrm{N}$ content regression model showed a good fit in the case of $H$. rhamnoides and P. tabulaeformis mixed forest.

\subsection{Relationship between soil microorganism biomass and soil environmental factors}

The sample sequences of all stands were clustered, and the results showed that the bacterial communities of the samples consisted of 36 phyla, 78 classes, 148 orders, 276 families, 464 genera, and 900 species. At the level of similarity of $0.97,2922$ operational taxonomic units (OTUs) were classified in the bacterial samples. The fungal communities of the samples consisted of 10 kingdoms, 27 phyla, 46 classes, 71 orders, 88 families, 96 genera, and 132 species. At the level of similarity of 0.97, 2922 OTUs were classified in the fungal samples. Each OTU has its corresponding species, and many different OTUs correspond to the same species. Combining OTUs of the same species and statistically analyzing the changes of species composition among different samples enables the diversity of microflora among different samples to be understood.

\subsubsection{Difference analysis of soil bacterial communities in different $H$. rhamnoides forests}

\subsubsection{One-way ANOVA of soil bacteria in H. rhamnoidesforests}

To analyze whether the number of bacteria in the top ten rankings was affected significantly by different stands at the phylum level, we used one-way ANOVA to analyze the significance of five stands, specifically, $H$. rhamnoides pure forest (shady slope), H. rhamnoidespure forest (sunny slope), H. rhamnoides and Chinese arborvitae mixed forest, and H. rhamnoides and P. tabulaeformis mixed forest and grassland, as shown in Figure 1. From Figure 1, it can be seen that the top ten bacterial species in the soil community have the highest significance level of 0.9449 (Firmicutes) and the lowest value of 0.1188 (Chloroflexi) under different stands. There is no significant difference between different bacterial species under different stands. 
To analyze whether different soil layers have a significant effect on the number of bacteria in the top ten rankings, we used one-way ANOVA to analyze the number of bacteria in the top ten rankings of soil bacterial community abundance in 0-10 cm, 10-20 cm, and 20-40 cm soil layers. The results are shown in Figure 2. As can be seen in the figure, there is a significant difference between Nitrospirae and Bacteroidetes at the level of 0.01, while GAL15 was significantly different at the level of 0.05. Comparing the one-way ANOVA under different stands reveals that the difference between different stands in the area studied was smaller than was that between different soil layers.

\subsubsection{Correlation analysis of main soil bacteria and environmental factors in $H$. rhamnoides forests}

We used the Pearson correlation coefficient to analyze the correlation between bacterial phyla and soil environmental factors in bacterial communities. The results of the analysis are illustrated by a heatmap in Figure 3. The figure shows that TOC, AN, EP, and AK have a strong influence on the content of bacteria in soil. The dominant populations, Gemmatimonadetes, Nitrospirae, and Actinobacteria, were negatively correlated with TOC, AN, EP, and AK. Gracilibacteria, Parcubacteria, and WS2 were positively correlated with TOC, AN, EP, and AK.

\subsubsection{Difference analysis of soil fungal communities in different $H$. rhamnoides forests}

\subsubsection{One-way ANOVA of soil fungal communities in H. rhamnoides forests}

To ascertain whether the number of fungi in the top five rankings was affected significantly by different stands at the gate level, we used one-way ANOVA to analyze the significance of the above five stands; the results were shown in Figure 4. The figure shows that the top five bacterial species in the soil fungal community have a highest significant level of 0.9562 (Firmicutes) and a lowest value of 0.06994 (Chloroflexi) under different stands, so there is no significant difference among different bacterial species under different stands.

We used one-way ANOVA to analyze the number of fungi in the top ten of soil fungi abundance rankings in $0-10 \mathrm{~cm}, 10-20 \mathrm{~cm}$, and $20-40 \mathrm{~cm}$ soil layers. The results are shown in Figure 5. The figure reveals a significant difference in Ciliophora, at the 0.001 level, and Chytridiomycota, at the 0.01 level. Comparing the one-way ANOVA under different stands shows that the difference between different stands in the area studied is smaller than is that between different soil layers.

\subsubsection{Correlation analysis of main soil fungal and environmental factors in $\boldsymbol{H}$. rhamnoides forests}

We used the Pearson correlation coefficient to analyze the correlation between bacterial phyla and soil environmental factors in fungal communities. The results of the analysis are illustrated by a heatmap in Figure 6. The figure shows that the soil environment has little effect on the biomass of the fungal population. Ichthyosporea and Ciliophora were positively correlated with soil environmental factors, Ascomycota was negatively correlated with TP, Cercozoa was negatively correlated with TN and AN, and Glomeromycota was negatively correlated with TK.

Generally speaking, compared with the bacterial community, the Pearson correlation between the fungal community and soil environmental factors is lower in H. rhamnoides forest; that is, environmental factors have a greater impact on bacteria than on fungi. Conversely, the number of species of bacteria in the soil under the $H$. rhamnoides forest is higher than is that of fungi, which may be why there are more bacteria in the bacterial community that are related significantly to environmental factors.

\section{Discussion}

Based on analysis of microbial biomass $\mathrm{C}$ and $\mathrm{N}$ in H. rhamnoidespure forest (shady slope), H. rhamnoides pure forest (sunny slope), H. rhamnoides and Chinese arborvitae mixed forest, and H. rhamnoides and Pinus tabulaeformis mixed forest, we examined the driving capacity of the soil carbon (C) cycle and the mineralization and fixation of soil microorganisms on nitrogen $(\mathrm{N})$. The soil microbial $\mathrm{C}$ and $\mathrm{N}$ analysis 
showed that soil microbial biomass $\mathrm{N}$ and $\mathrm{N}$ in different forest layers exhibited a trend of a small change with increasing soil layers; that is, as the soil depth increased, the soil microbial activity weakened gradually. A one-way ANOVA analysis of the soil microbial community showed that the difference in the soil microbial communities among different forests in the study area was smaller than was that in different soil layers. Gracilibacteria, Gemmatimonadetes, Nitrospirae, Parcubacteria, and Actinobacteria are highly correlated with most of the soil environmental factors, and Ichthyosporea and Ciliophora in fungi are correlated strongly with most of the environmental factors and are affected greatly by them. Compared with the bacterial community, the Pearson correlation between the fungal community and soil environmental factors is lower; that is, environmental factors have a greater effect on bacteria than on fungi. Conversely, the study found more species of bacteria than of fungi in the soil under the H. rhamnoides forest, which may be why there are more bacteria in the bacterial community that are significantly related to environmental factors.

Restoration mainly affects the quantity and community of soil microorganisms by affecting the litter, root morphology and secretion, and the material and energy transformation process in the whole ecosystem. To better analyze the mechanism of influence of vegetation on microorganisms and the influence of site conditions and environmental factors on soil microbial community diversity, the litter and root exudates under various $H$. rhamnoides forests can be studied further.

This study only addressed the soil microbial characteristics of $H$ rhamnoides forest in the process of revegetation in Wuqi, Shaanxi Province. To better analyze the microbial characteristics of $H$. rhamnoides forest under the effect of revegetation in the Loess Plateau, similar studies can be conducted in other areas of the Loess Plateau. The results of these experiments can be analyzed to better explore the soil under H. rhamnoides forest in the process of vegetation diversity of soil microbial community and is expected to provide some data supporting the study of revegetation in the Loess Plateau.

\section{Acknowledgements}

Our work was financially supported by the National Science and Technology Support Program of China (2016YFC0501705).

\section{References}

Chen, Y., Cao, Y., 2014. Response of tree regeneration and understory plant species diversity to stand density in mature Pinus tabulaeformis plantations in the hilly area of the Loess Plateau, China. Ecological engineering 73, 238-245.

Chen, Y., Wang, K., Lin, Y., Shi, W., Song, Y., He, X., 2015. Balancing green and grain trade. Nature Geoscience 8, 739-741.

David A. Wardle, Lawrence R. Walker, Richard D. Bardgett, 2004. Ecosystem Properties and Forest Decline in Contrasting Long-Term Chronosequences. Science 305,509-519.

Deng, L., Shangguan, Z., Sweeney, S., 2015. "Grain for Green" driven land use change and carbon sequestration on the Loess Plateau, China. Scientific Reports 4,1-8.

Ding, X., Zhang, B., Lu, X., Wang, J., Horwath, W.R., 2017. Parent material and conifer biome influence microbial residue accumulation in forest soils. Soil Biology and Biochemistry 107, 1-9.

Feng, X., Fu, B., Lu, N., Zeng, Y., Wu, B., 2013. How ecological restoration alters ecosystem services: an analysis of carbon sequestration in China's Loess Plateau. Scientific Reports 3,1-5.

Feng, X., Fu, B., Piao, S., Wang, S., Ciais, P., Zeng, Z., Lu, Y., Zeng, Y., Li, Y., Jiang, X., Wu, B., 2016. Revegetation in China's Loess Plateau is approaching sustainable water resource limits. Nature Climate Change 6, 1019-1022.

Fierer, N., Jackson, R.B., 2006. The Diversity and Biogeography of Soil Bacterial Communities. Proceedings of the National Academy of Sciences of the United States of America 103, 626-631. 
Hu, C., Guo, L., Liu, G., 2014. Soil microbial community structure under different vegetation restoration patterns in the loess hilly area. Acta Ecologica Sinica 34(11), 2986-2995.

Hu, J., 2012.Present Situation and Development Prospect of Hippophae rhamnoides Resources. Gansu Science and Technology 28, 143-144.

Jiao, F., Wen, Z., An, S., Yuan, Z., 2013. Successional changes in soil stoichiometry after land abandonment in Loess Plateau, China. Ecological Engineering 58, 249-254.

Kou, M., Jiao, J., Yin, Q., Wang, N., Wang, Z., Li, Y., Yu, W., Wei, Y., Yan, F., Cao, B., 2016. Successional Trajectory Over 10 Years of Vegetation Restoration of Abandoned Slope Croplands in the Hill-Gully Region of the Loess Plateau. Land Degradation \& Development 27, 919-932.

Lewis, D.E., White, J.R., Wafula, D., Athar, R., Dickerson, T., Williams, H.N., Chauhan, A., 2010. Soil Functional Diversity Analysis of a Bauxite-Mined Restoration Chronosequence. Microbial Ecology 59, 710723.

Li, D., Liang, Y., Hou, X., Huang, J., Jiang, J., Ruan, C., Hao, D., Qi, J., 2003. Study on ecological function and benefit of Hippophae rhamnoides construction vegetation in Loess Plateau. Hippophae 16(3),16-211.

Luo, G., Zhao, T., Wang, X., Sun, B., Cao Z., 2006. Study on revegetation effect of returning farmland to forestry combining closure in sand covered and loess region in Wuqi County. Research of Soil and Water Conservation 13(3), 80-82.

Ma, L., Teng, Y., Shangguan, Z., 2014. Ecohydrological responses to secondary natural Populus davidiana and plantation Pinus tabulaeformis woodlands on the Loess Plateau of China. Ecohydrology 7, 612-621.

Nacke, H., Goldmann, K., Schoning, I., Pfeiffer, B., Kaiser, K., Castillo-Villamizar, G.A., Schrumpf, M., Buscot, F., Daniel, R., Wubet, T., 2016. Fine Spatial Scale Variation of Soil Microbial Communities under European Beech and Norway Spruce. Frontiers in Microbiology 7,1-14.

Nie, J., Stevens, T., Rittner, M., Stockli, D., Garzanti, E., Limonta, M., Bird, A., Ando, S., Vermeesch, P., Saylor, J., Lu, H., Breecker, D., Hu, X., Liu, S., Resentini, A., Vezzoli, G., Peng, W., Carter, A., Ji, S., Pan, B., 2015. Loess Plateau storage of Northeastern Tibetan Plateau-derived Yellow River sediment. Nature Communications 6,1-8.

Okubo, A., Matsusaka, M., Sugiyama, S., 2016. Impacts of root symbiotic associations on interspecific variation in sugar exudation rates and rhizosphere microbial communities: a comparison among four plant families. Plant and Soil 399, 345-356.

Pei, Z., Eichenberg, D., Bruelheide, H., Krober, W., Kuhn, P., Li, Y., von Oheimb, G., Purschke, O., Scholten, T., Buscot, F., Gutknecht, J.L.M., 2016. Soil and tree species traits both shape soil microbial communities during early growth of Chinese subtropical forests. Soil Biology and Biochemistry 96, 180-190.

Prescott, C.E., Grayston, S.J., 2013. Tree species influence on microbial communities in litter and soil: Current knowledge and research needs. Forest Ecology and Management 309, 19-27.

Ren, C., Chen, J., Lu, X., Doughty, R., Zhao, F., Zhong, Z., Han, X., Yang, G., Feng, Y., Ren, G., 2018. Responses of soil total microbial biomass and community compositions to rainfall reductions. Soil Biology and Biochemistry 116, 4-10.

Song, X., Peng, C., Zhou, G., Jiang, H., Wang, W., 2015. Chinese Grain for Green Program led to highly increased soil organic carbon levels: A meta-analysis. Scientific Reports 4,1-7.

Spohn, M., Widdig, M., 2017. Turnover of carbon and phosphorus in the microbial biomass depending on phosphorus availability. Soil Biology and Biochemistry 113, 53-59.

Ushio, M., Balser, T.C., Kitayama, K., 2013. Effects of condensed tannins in conifer leaves on the composition and activity of the soil microbial community in a tropical montane forest. Plant and Soil 365, 157-170. 
Van der Heijden, M.G.A., Bardgett, R.D., van Straalen, N.M., 2008. The unseen majority: soil microbes as drivers of plant diversity and productivity in terrestrial ecosystems. Ecology Letters 11, 296-310.

Xing, X., Huang, Y., An, Sh., Yan, H., 2013. Characteristics of physiological groups of soil nitrogentransforming microbes in different vegetation types in the Loess Gully region, China. Acta Ecologica Sinica 33(18), 5608-5614.

Zeng, Q., Dong, Y., An, S., 2016. Bacterial Community Responses to Soils along a Latitudinal and Vegetation Gradient on the Loess Plateau, China. PLoS One 11,1-17.

Zeng, X., Zhang, W., Cao, J., Liu, X., Shen, H., Zhao, X., 2014. Changes in soil organic carbon, nitrogen, phosphorus, and bulk density after afforestation of the "Beijing-Tianjin Sandstorm Source Control" program in China. Catena 118, 186-194.

Zhalnina, K., Dias, R., de Quadros, P.D., Davis-Richardson, A., Camargo, F.A.O., Clark, I.M., McGrath, S.P., Hirsch, P.R., Triplett, E.W., 2015. Soil pH Determines Microbial Diversity and Composition in the Park Grass Experiment. Microbial Ecology 69, 395-406.

Zhang, C., Liu, G., Xue, S., Wang, G., 2016. Soil bacterial community dynamics reflect changes in plant community and soil properties during the secondary succession of abandoned farmland in the Loess Plateau. Soil Biology and Biochemistry 97,40-49.

Zhang, C., Liu, G., Song, Z., Wang, J., Guo, L., 2018. Interactions of soil bacteria and fungi with plants during long-term grazing exclusion in semiarid grasslands. Soil Biology and Biochemistry 124, 47-58.

Zhang, H., Tang, M., Chen, H., Zheng, C., 2010. Effects of inoculation with ectomycorrhizal fungi on microbial biomass and bacterial functional diversity in the rhizosphere of Pinus tabulaeformis seedlings. European Journal of Soil Biology 46, 55-61.

Zhao, X., Li, Z., Robeson, M.D., Hu, J., Zhu, Q., 2018. Application of erosion-resistant fibers in the recovery of vegetation on steep slopes in the Loess Plateau of China. Catena 160, 233-241.

Table captions

Table 1 Site conditions and vegetation composition

Table 2 Characteristics of soil microbes carbon and nitrogen in H. rhamnoides forests

Table 3 Regression analysis of soil microbial carbon and nitrogen and soil environmental factors in $H$. rhamnoides forests

Figure captions

Figure 1. One-way ANOVA of H. rhamnoides forests' top 10 bacteria

Figure 2. One-way ANOVA of $\boldsymbol{H}$. rhamnoides forests' top 10 bacteria

Figure 3. Heatmap of bacterial and environmental factors in $H$. rhamnoides forests

Annotation:The $\mathrm{X}$-axis and $\mathrm{Y}$-axis of the heatmap are environmental factors and species, respectively. $\mathrm{R}$ and $\mathrm{P}$ values are obtained by calculation. The $\mathrm{R}$ value is shown in different colors in the graph. The color card on the right-hand side of the heatmap is a color partition with different $\mathrm{R}$ values. $0.01<\mathrm{p}$ [?] $0.05 *$ $0.001<\mathrm{p}$ [?] $0.01 * * \mathrm{p}$ [?] $0.001 * * *$.

Figure 4. One-way ANOVA of H. rhamnoides forests' top five fungi

Figure 5. One-way ANOVA of H. rhamnoides forests' top 10 fungi

Figure 6. Heatmap of fungi and environmental factors in $H$. rhamnoides forests

Annotation:The $\mathrm{X}$-axis and $\mathrm{Y}$-axis of the heatmap are environmental factors and species, respectively. $\mathrm{R}$ and $\mathrm{P}$ values are obtained by calculation. The $\mathrm{R}$ value is shown in different colors in the graph. The color 
card on the right-hand side of the heatmap is a color partition with different $\mathrm{R}$ values. $0.01<\mathrm{p}$ [?] 0.05 * $0.001<\mathrm{p}$ [?] $0.01 * * \mathrm{p}[?] 0.001 * * *$.

\section{Hosted file}

Tables.docx available at https://authorea.com/users/329866/articles/456734-typicalartificial-hippophae-rhamnoides-forest-soil-microbial-response-to-the-soil-environmentof-abandoned-cropland-in-the-loess-plateau

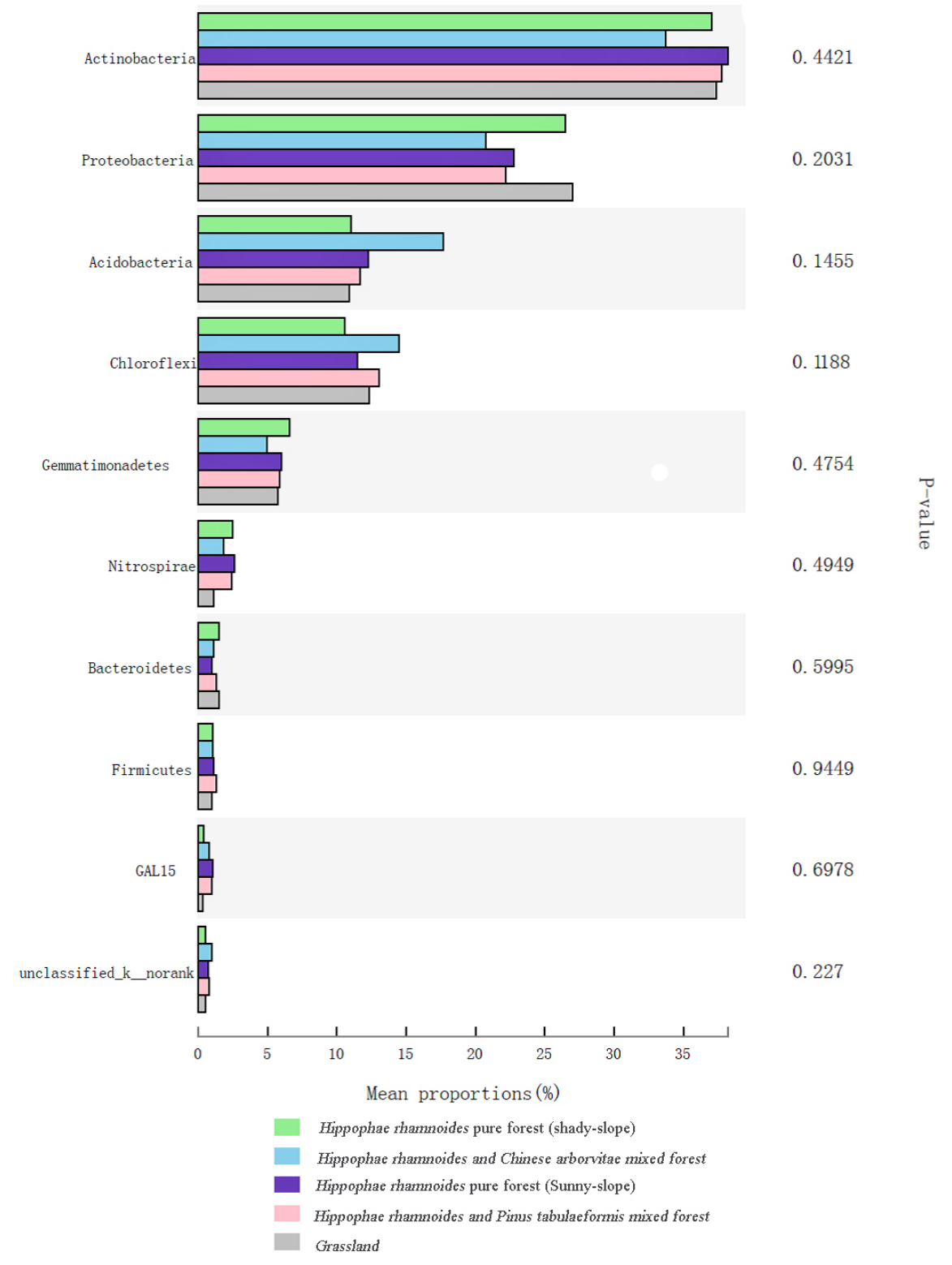




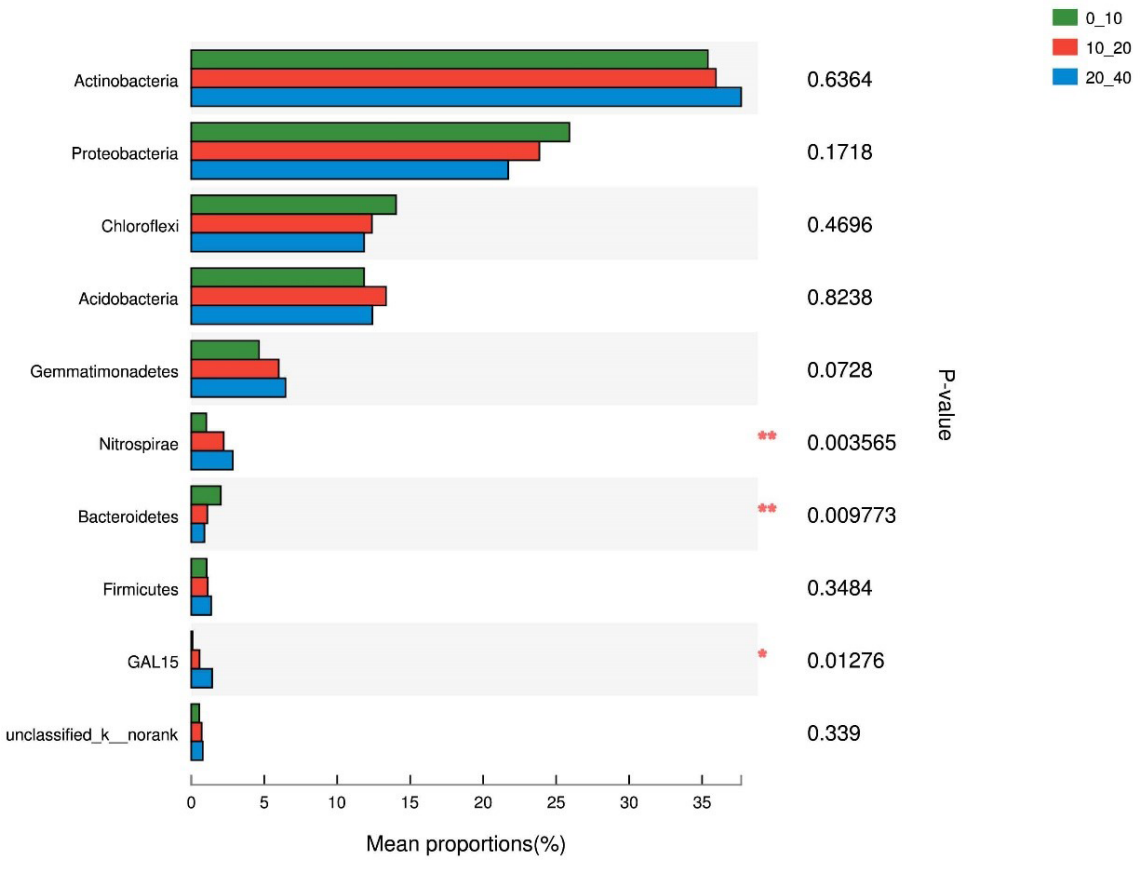




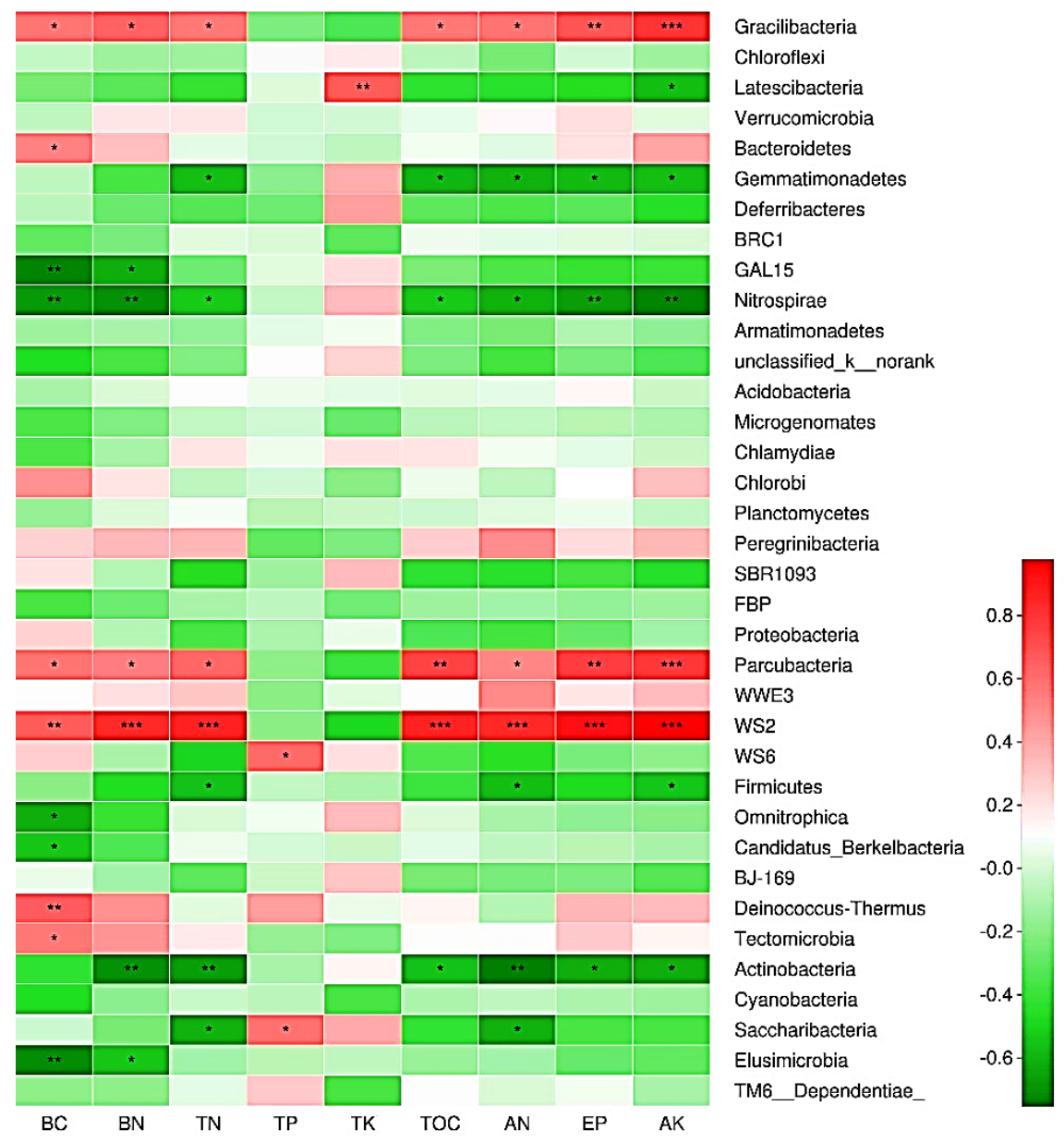




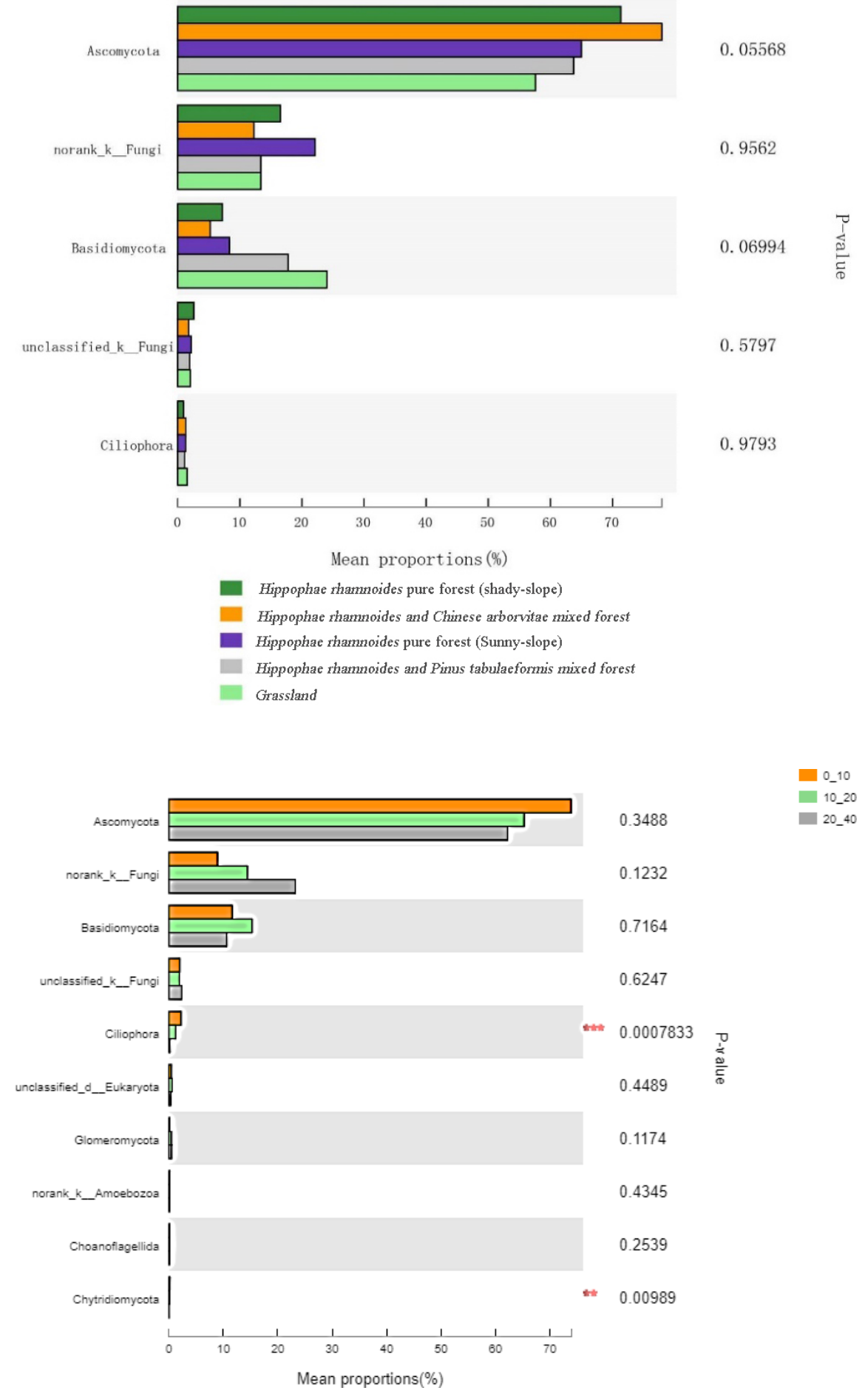




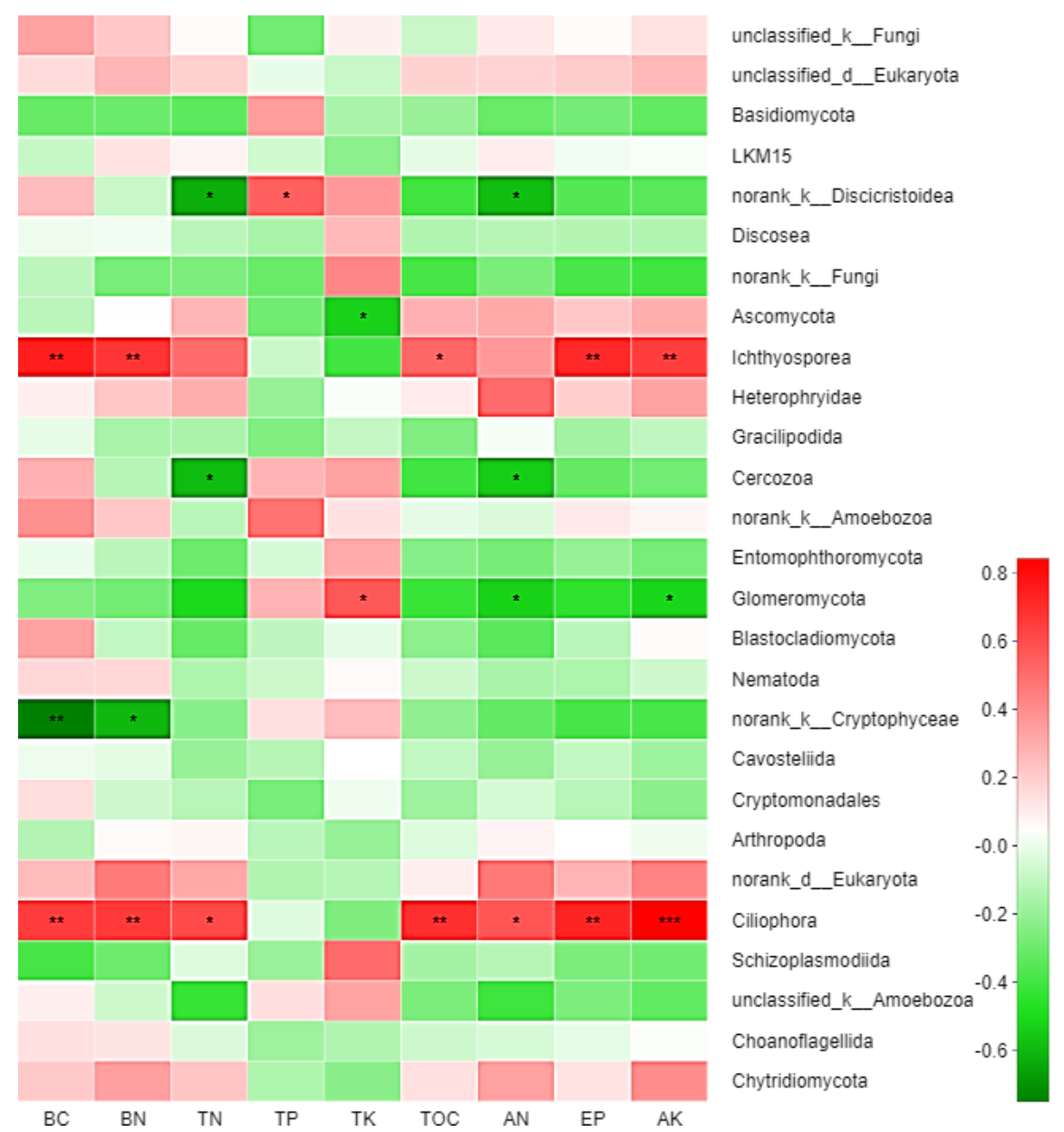

